\title{
\#fiqueemcasa - Perspectivas de famílias sobre o auxílio em tarefas escolares de matemática durante a pandemia de Covid-19
}

\section{\#stayhome - Family perspectives in helping math school assignments during the Covid-19 pandemic}

\author{
${ }^{1}$ Francieli Aparecida Prates dos Santos francieli.prates.fp@gmail.com \\ 2 Klinger Teodoro Ciríaco \\ ${ }^{3}$ Natália Sevilha Stofel
}

\section{RESUMO}

Nos últimos meses, diversos países em distintos continentes estão reinventando seus modos de vida e, consequentemente, de acesso à educação que, ao que tudo indica, parece ter encontrando no ensino à distância, com o pressuposto apoio familiar, uma alternativa de trabalho. O objetivo deste texto é identificar as perspectivas de como famílias, de crianças matriculadas no ciclo da alfabetização em uma escola pública de São Carlos-SP, auxiliam nas atividades remotas ligadas ao ensino de Matemática durante o isolamento social provocado pela COVID-19. Partimos de reflexões produzidas na primeira fase de uma pesquisa de mestrado em Educação Matemática, a qual pretende identificar estratégias adotadas para resolução de problemas matemáticos. Acreditamos que um estudo específico sobre processos em situações de ensino em casa permite contribuir com o debate teórico-metodológico ao abordar uma temática ainda pouco explorada nas pesquisas: a relação família-escola.

Palavras-chave: COVID-19. Resolução de problemas matemáticos. Relação família-escola.

\begin{abstract}
In recent months, several countries on different continents are reinventing their ways of life and, consequently, of access to education which, it seems, they have found in distance education, with the assumption of family support, an alternative work. The objective of this text is to identify the perspectives of how families, of children enrolled in the literacy cycle in a public school in São Carlos-SP, assist in remote activities related to the teaching of Mathematics during the social isolation caused by COVID-19. We start from reflections produced in the first phase of a Master's research in Mathematics Education, which intends to identify strategies adopted to solve mathematical problems. We believe that a specific study on processes in home teaching situations allows us to contribute to the theoretical-methodological debate by addressing a theme still little explored in research: the family-school relationship.
\end{abstract}

Keywords: COVID-19. Resolution of mathematical problems. Family-school relationship.

1 Instituto de Matemática - INMA, Universidade Federal de Mato Grosso do Sul - UFMS, Campo Grande-MS.

2 Universidade Federal de São Carlos - UFSCar, São Carlos. Departamento de Teorias e Práticas Pedagógicas - DTPP.

3 Universidade Federal de São Carlos - UFSCar, São Carlos. Departamento de Enfermagem - DEnf. 


\section{INTRODUÇÃO}

O artigo em questão refere-se ao trabalho de pesquisa de campo, parte de uma dissertação vinculada ao Programa de Pós-Graduação em Educação Matemática, do Instituto de Matemática (INMA), da Universidade Federal de Mato Grosso do Sul - UFMS, Campo Grande - MS. Intencionamos trazer à tona reflexões do processo de aproximação com famílias na perspectiva de compreensão de como tem sido o auxílio nas atividades remotas no período de isolamento social.

A investigação localiza-se no campo da Psicologia da Educação Matemática, especificamente nos estudos da Psicologia Cognitiva, em que se toma como objetivo principal compreender em que medida o conhecimento matemático de famílias das camadas populares, mobilizados ao auxiliarem nas tarefas escolares, influencia o sentido de número (MCINTOSH; REYS; REYS, 1992) em situações de cálculo de crianças matriculadas em uma turma do $2^{\circ}$ ano do Ensino Fundamental de uma escola pública de São Carlos-SP.

Para este texto, apresentamos um recorte temático, o qual pretendeu identificar como as famílias reorganizaram suas rotinas, hábitos de higiene, como também se orientam para o auxílio nas atividades encaminhadas pelas professoras ligadas à Matemática durante o isolamento social, suas dificuldades de ensino e perspectivas frente à pandemia de COVID-19.

\section{O PROBLEMA DA PESQUISA}

Existe um debate nas ciências sociais sobre se a verdade e a qualidade das instituições de uma dada sociedade se conhecem melhor em situações de normalidade, de funcionamento corrente, ou em situações excepcionais, de crise. Talvez os dois tipos de situação sejam igualmente indutores de conhecimento, mas certamente que nos permitem conhecer ou relevar coisas diferentes. Que potenciais conhecimentos decorrem da pandemia do coronavírus? (SANTOS, 2020, p. 05).

No decorrer dos últimos meses, o cenário mundial do qual estávamos familiarizados sofreu grande impacto devido à propagação de um novo vírus, este reconhecido pela Organização Mundial da Saúde (OMS) como “COVID-194 ”. Desde então, vários países, de diferentes continentes, vêm modificando seus hábitos de higiene, modos de produção de vida e tomando outras formas de direcionamento dos setores econômicos, sociais, políticos e educacionais. Conforme informações da Organização Pan-Americana da Saúde (OPAS), em 31 dezembro de 2019 a OMS recebeu um alerta de várias ocorrências de pneumonia na cidade de Wuhan, província de Hubei na República Popular da China. Entretanto, essa pneumonia se tratava de um novo tipo de coronavírus que nunca havia sido identificado em seres humanos anteriormente.

Na primeira semana do ano de 2020, houve um alerta emitido pelas autoridades chinesas para o mundo, concretizava em sua comunicação a primeira morte pelo novo vírus em Wuhan, cidade que nas semanas seguintes veio a se tornar o epicentro da crise, ficando em quarentena, assim fechada para o mundo exterior, na segunda semana de janeiro de 2020 a OMS notificava o primeiro caso de uma pessoa infectada fora da China pela COVID-19. Em janeiro de 2020, de acordo com OMS, por conta do surto da doença causada pela COVID-19, foi decretado uma emergência de saúde pública de importância internacional. Por consequência disso, essa nova configuração se tornou de mais alto nível de alerta das organizações de saúde, se caracterizando, em março deste ano, como uma pandemia pela OMS.

4 Segundo a Fundação Oswaldo Cruz o novo coronavírus é chamado oficialmente de COVID-19 porque COVID significa Corona Vírus Disease (Doença do Coronavírus) enquanto o "19" se refere ao ano 2019 por conta que foi quando surgiram os primeiros casos em Wuhan na China. 
Conforme a OPAS, o termo "pandemia" refere-se à distribuição geográfica de uma doença e não à sua gravidade. Trata-se de uma epidemia que é amplamente disseminada e que ocorre em vários países e continentes do mundo ao mesmo tempo (OPAS, 2020). Com base em informações do Ministério da Saúde do Brasil, pode-se dizer que uma das características do vírus é de apresentar um quadro clínico que varia de infecções assintomáticas e quadros respiratórios graves, tem por sintomas mais comuns: tosse, coriza, febre, dor de garganta e dificuldade para respirar. Sua transmissão acontece de um indivíduo doente para o outro por contato próximo, um simples toque de aperto de mão, espirro, gotículas de saliva, dentre outros, são meios de infecção. Além disso, há registro de que o vírus ainda pode estar presente em superfícies, corrimãos, maçanetas, brinquedos, etc. (BRASIL, 2020).

Para entender melhor como a COVID-19 chegou ao Brasil, foi desenvolvido um estudo intitulado "Routes for COVID-19 importation in Brazil” (CANDIDO; WATTS; ABADE; KRAEMER; PYBUS; CRODA; OLIVEIRA; KHAN; SABINO; FARIA, 2020). Uma das conclusões deste trabalho foi que a maioria dos casos de COVID-19, importados para o Brasil, foi de pessoas infectadas em viagens internacionais, mais precisamente vindas da Itália. Especificamente, passageiros com desembarque em São Paulo (SP) de voos vindo do continente europeu, entre outros países, o que contribui para a capital e o Estado de SP serem, atualmente, o epicentral da pandemia em nosso país (CANDIDO et al., 2020).

Diante do quadro do vírus se agravando no Brasil e, particularmente, em São Paulo, o governador do Estado, no Decreto $\mathrm{N}^{\circ}$ 64.881, de 22 de Março de 2020, decretou quarentena em todo território paulista por conta do novo contexto da pandemia. Para este fim, considerando a Lei Federal n ${ }^{\circ}$ 13.979, de 6 de Fevereiro de 2020, “[...] ao dispor sobre medidas para o enfrentamento da citada emergência, inclui a quarentena (art. 2º II), a qual abrange a restrição de atividades (...) de maneira a evitar possível contaminação ou propagação do coronavírus” (SÃO PAULO, 2020, p. 1a). Cabe destacar que um dos decretos, publicados no Diário Oficial do Estado de São Paulo, pelo governador João Agripino da Costa Doria Junior (PSDB), sobre medidas para o enfrentamento à pandemia, o resguardo dos exercícios presenciais e funcionamento de serviços públicos não essenciais como, por exemplo, o Decreto n ${ }^{\circ}$ 64.862, de 13 de Março de 2020, foi determinada "[...] a suspensão das aulas no âmbito da Secretária da Educação [...]” (SÃO PAULO, 2020, p. 1).

Face a tal medida, as escolas da rede estadual de educação passaram a exercer suas atividades de forma remota a partir da ação de diferentes canais de comunicação como, por exemplo, YouTube no canal do "Centro de Mídias-SP”, no Facebook na página “Centro de Mídias Educação Infantil e Anos Iniciais”, bem como por meio de propostas de atividades encaminhadas no Google Classroom e na TV aberta no canal da Universidade Virtual do Estado de São Paulo (UNIVESP), os quais visam interagir com as crianças e suas respectivas famílias, uma vez que ficou à cargo de mães, pais e/ou responsáveis o processo de reorganização da rotina de estudos (em casa) dos alunos durante a suspensão das aulas presenciais.

Devido ao isolamento social, provocado pela COVID-19, a continuidade das atividades ligadas ao processo educacional escolar formal, como vimos, adotou novas formas de organização. Escolas, professores, famílias e alunos, agora têm de repensar formas de interação, problematização do conhecimento e, consequentemente, avaliação da aprendizagem, dentre as quais destacamos a Matemática, objeto de interesse ao estudo que estamos a desenvolver. Dentre as tarefas encaminhadas à casa, nosso interesse centra-se naquelas que dizem respeito às questões numéricas, que envolvem procedimentos de cálculo, uma vez que este é adquirido ao longo de experiências informais e formais, portanto, no âmbito escolar ou fora dele, essa habilidade se constitui em demostrar capacidade com o cálculo mental, estimativas e quantidades numéricas, assim Macintosh, Reys e Reys (1992, p. 3) definem "sentido de número" como uma compreensão geral dos sujeitos “[...] sobre os números e as operações, juntamente com a capacidade e inclinação para usar essa compreensão de modo flexível, para fazer juízos matemáticos e para desenvolver estratégias úteis para lidar com os números e com as operações”. 
Compreendemos que o período de isolamento social é essencial para que possamos identificar como as famílias estão a lidar com as atividades escolares das crianças, formas de interações com a escola e ainda possíveis dificuldades no processo. Como a figura do educador não está presente fisicamente, surge possibilidade maior de interação entre o grupo familiar e as crianças, para que ajudem estas nas resoluções de problemas matemáticos propostos para o período. Trabalhos anteriores como, por exemplo, os de Espíndola e Souza (2010) reforçam o potencial de investigações que buscam conhecer contextos/práticas socioculturais de letramento e letramento matemático inerentes às relações família-escola, o que presumimos ocorrer no caso de nosso trabalho, também.

As formas de interação e as estratégias utilizadas em tarefas numéricas em casa são recurso basilar para que as crianças alcancem uma aprendizagem matemática significativa, pois o ensino se estenderá das salas de aulas, via remotamente, para o interior de suas residências. Neste contexto, alguns requisitos para o desempenho das famílias nesse momento, tornam-se relevantes: 1) acesso à internet e inclusão digital; 2) responsabilidade e compromisso com a rotina de estudo em casa; e 3) conhecimentos informais e formais de conteúdos matemáticos ligados à Aritmética.

A flexibilização do ensino durante o isolamento social, decretado pelo Estado de São Paulo, bem como em outras regiões brasileiras, trouxe desafios e levantou problemas importantes e necessários ao debate da estruturação metodológica de qualidade da implementação do processo de reorganização do cotidiano escolar e familiar. Neste contexto geral, as dúvidas são muitas, mas, algumas premissas vão tornando-se certezas: o tempo-espaço que estamos vivendo, devido a crise de saúde pública e transmissão comunitária do vírus, não tem previsão de se findar tão logo; as crianças precisam seguir aprendendo e tendo acesso à cultura; os/as professores/professoras se desdobram para dar conta do planejamento virtual e acompanhamento das interações com as famílias; e o ensino de Matemática caminha para a incorporação de novos recursos no que respeita à aprendizagem. Devido a COVID-19, com o isolamento social e suspensão das aulas presenciais, acreditamos que “[...] a responsabilidade pela aprendizagem, ou pelo menos, para uma aprendizagem mais satisfatória da leitura, da escrita e da matemática, acaba ficando, grande parte das vezes, a cargo das famílias e do próprio aprendiz” (ESPÍNDOLA; SOUZA, 2010, p. 71).

Enfim, parece-nos, agora mais do nunca, que o conhecimento da cultura matemática das famílias será de fundamental importância à demanda que se coloca em debate: Como as famílias auxiliam as crianças nas atividades numéricas? Que recursos utilizam neste processo? Quais limites, dificuldades e perspectivas? É por compreender a relação família-escola como pressuposto à efetivação de práticas colaborativas em que o diálogo se firme de forma pacífica, em regime de corresponsabilidade pelo desempenho nas tarefas escolares e níveis de proficiência das crianças, que acreditamos ser importante um estudo contemporâneo que visa perceber como anda a Educação Matemática em tempos de pandemia.

\section{PROCEDIMENTOS METODOLÓGICOS}

Os dados coligidos e apresentados referem-se à fase inicial da produção de dados. Para alcançar o objetivo deste estudo, tomamos como base os pressupostos de Bogdan e Biklen (1994), uma vez que o trabalho se inscreve no campo da pesquisa qualitativa em educação. A pesquisa qualitativa proporciona ao pesquisador “[...] estabelecer estratégias e procedimentos que lhes permitam tomar em consideração as experiências do ponto de vista do informador [...]” (BOGDAN; BIKLEN, 1994, p. 51).

No cenário do trabalho que desenvolvemos, para se verificar que está "por trás” das estratégias mobilizadas pelas famílias no auxílio nas tarefas de Matemática, alguns instrumentos de produção de dados foram adotados, atendendo as recomendações de saúde no sentido do distanciamento social, prática essa valiosa para não propagação do vírus, sendo eles: 1) mapeamento das famílias para participação voluntária na pesquisa com auxílio das professoras de turmas do $2^{\circ}$ ano do Ensino Fundamental da escola parceira do projeto, da rede esta- 
dual de ensino de São Carlos-SP; e 2) entrevista virtual inicial com as mães das crianças. Conforme dito, tudo fora feito à distância, pela internet e por videochamadas no aplicativo WhatsApp. As famílias são representadas aqui pelas Mulheres, as quais são identificadas como M 1, M 2 e M 3, respectivamente. As crianças (os filhos) são alunos de turmas diferentes, porém, da mesma instituição de ensino.

O quadro 1 caracteriza o perfil das mulheres entrevistadas:

Quadro 1 - Caracterização das famílias

\begin{tabular}{|c|c|c|c|c|}
\hline Identificação & Idade & Escolaridade & $\begin{array}{c}\text { Renda média familiar I Número de } \\
\text { pessoas pertencentes ao grupo } \\
\text { familiar }\end{array}$ & $\begin{array}{c}\text { Quem auxilia no } \\
\text { dever de casa de } \\
\text { Matemática? }\end{array}$ \\
\hline M1 & 30 anos & $2^{\circ}$ Grau (Ensino Médio) & 1 a 2 salários mínimos/4 pessoas & Mulher (mãe) \\
\hline M2 & 35 anos & $2^{\circ}$ Grau (Ensino Médio) & 2 a 3 salários mínimos/4 pessoas & Mulher (mãe) \\
\hline M3 & 37 anos & $2^{\circ}$ Grau (Ensino Médio) & 2 a 3 salários mínimos/3 pessoas & Homem (pai) \\
\hline
\end{tabular}

Fonte: Elaborado pelos autores com base na entrevista, 2020.

Para além de dados de caracterização, foi possível, com a entrevista, compreendermos melhor os processos de mudança dos hábitos de higiene, de rotina com o processo de ensino remoto e as implicações deste para o dever de Matemática. Com o contato feito, criamos um grupo no WhatsApp para posterior acompanhamento das interações ocorridas no auxílio das tarefas. Para este fim, as mulheres foram orientadas a gravar vídeos curtos que possibilitem captar como são as indicações durante o estudo remoto, ou seja, os diálogos que estes realizam na mediação com seus filhos. Ao todo, temos 3 grupos em funcionamento, sendo 1 para cada família.

Os dados angariados na entrevista com as mulheres-mães serão descritos na próxima seção na tentativa de levantar indicadores analíticos a partir das percepções elegidas como objeto de apreciação neste artigo. Cabe salientar que para a publicação deste manuscrito, por envolver seres humanos na produção direta de dados, via entrevistas virtuais semiestruturadas, cumpre os princípios éticos contidos na Declaração de Helsinki, da World Medical Association (http://www.wma.net/e/policy/b3.htm), além do atendimento a legislações específicas, uma vez que o projeto de pesquisa localiza-se cadastrado na Plataforma Brasil (https://plataformabrasil.saude.gov. br) junto ao Comitê de Ética em Pesquisa da Universidade Federal de Mato Grosso do Sul - UFMS (CAAE: 15521419.6.0000.0021), haja vista que refere-se ao trabalho de mestrado acadêmico da primeira autora, sob orientação do segundo e com colaboração/revisão técnica-conceitual do campo das Ciências da Saúde, realizada pela terceira autora.

\section{DESCRIÇÃO E ANÁLISE PRELIMINAR DOS RESULTADOS}

Para a descrição e análise das informações coligidas, não podemos nos eximir do tempo presente em que contexto histórico-político-social exige formas de resistência e, mais do nunca, de luta para que possamos compreender, como destaca Boaventura de Sousa Santos, que a “[...] actual pandemia não é uma situação de crise claramente contraposta a uma situação de normalidade” (2020, p. 5), isso porque: 
Desde a década de 1980 - à medida que o neoliberalismo se foi impondo como a versão dominante do capitalismo e este se foi sujeitando mais e mais à lógica do sector financeiro-, o mundo tem vivido em permanente estado de crise. Por um lado, a ideia de crise permanente é um oximoro, já que, no sentido etimológico, a crise é, por natureza, excepcional e passageira, e constitui a oportunidade para ser superada e dar origem a um melhor estado de coisas. Por outro lado, quando a crise é passageira, ela deve ser explicada pelos factores que a provocam. Mas quando se torna permanente, a crise transforma-se na causa que explica tudo o resto. Por exemplo, a crise financeira permanente é utilizada para explicar os cortes nas políticas sociais (saúde, educação, previdência social) ou a degradação dos salários. E assim obsta a que se pergunte pelas verdadeiras causas da crise (SANTOS, 2020, p. 5).

Seguindo a linha de raciocínio de Santos (2020), nos indagamos, no caso do Brasil: o que a pandemia de COVID-19 revela sobre as desigualdades sociais e educacionais de sua população? Para nós, em concordância com o autor, basicamente, destaca, de forma explícita, dois lados de uma mesma moeda: "[...] legitimar a escandalosa concentração de riqueza e boicotar medidas eficazes para impedir a iminente catástrofe ecológica" (SANTOS, 2020, p.06).

Em relação às famílias, cujas mulheres foram entrevistadas, fica em evidência estas questões, bem como aspectos ligados a falta de informações concretas e confiáveis em relação ao novo coronavírus e as formas de prevenção. Outros fatores importantes são o excesso de informações e a dificuldade em encontrar fontes seguras.

Ultimamente a televisão em casa a gente não liga mais. Eu vejo no Facebook só, o WhatsApp que o essencial e virou caso de necessidade. M3 (Entrevista Concedida em 13/05/2020).

Acho que as matérias que sai nos jornais não são todas confiáveis. M2 (Entrevista Concedida em 13/05/2020).

Em casos de pandemia ou outras necessidades urgentes em saúde coletiva, ter ou não informação pode determinar ficar ou não doente. Porém, houve nos últimos anos a criação e propagação das fake news. No caos da pandemia de COVID-19, tão rápida quanto a propagação do vírus, foi a de notícias falsas que variam desde causas, sintomas, tratamentos e formas de prevenção (SOUSA JÚNIOR; RAASH; SOARES, 2020). As entrevistadas destacaram familiaridade com o uso do celular, por exemplo, para obtenção de notícias e busca por informações em relação ao vírus, contudo, devido aos tempos em que estamos viver, concordamos com Sawaia (2020, p. 4), quando a autora destaca que:

Não é possível cultivar afetos alegres quando decisões sobre a saúde do povo fazem parte do jogo eleitoreiro e da disputa geopolítica, como a discussão sobre uma das medicações possíveis (mas não cientificamente comprovada em termos de uso global) de combate à covid19, a hidroxicloroquina, virar um debate ideológico.

Nossa preocupação, enquanto profissionais da educação e da saúde, parte das declarações expostas de que o "WhatsApp" é mecanismo essencial de informação acerca da pandemia, como destacado por uma das mulheres. Sabemos que tal meio de comunicação tem sido instrumento de disseminação de notícias falsas, acentuadamente a partir de 2018, logo a busca e a produção de sentidos para o momento presente implicam reconhecer que este não é um mecanismo confiável para se informar. "As mensagens falsas relacionadas ao novo Coronavírus estão espalhando desinformação e medo, o que acaba atrapalhando o trabalho dos órgãos envolvidos na contenção desse novo vírus” (SOUSA JÚNIOR; RAASH; SOARES, 2020, p. 332).

Os últimos acontecimentos do cenário brasileiro nos colocam na necessidade de afirmar que, ao invés de se pensar na implementação tanto de medidas de prevenção para a população, quanto alinhar processos que demarquem caminhos para amenizar problemas sociais que tocam, por exemplo, a educação durante a pandemia, a pauta governamental tem, claramente, outros objetivos. "Por isso, a pandemia vem apenas agravar uma situação de crise a que a população mundial tem vindo a ser sujeita” (SANTOS, 2020, p. 6). 
“A Pedagogia do vírus” colocou muitas famílias brasileiras em situação de maior vulnerabilidade. Trouxe problemas econômicos, agravara o desemprego e revelara que o discurso meritocrático, no que respeita processos de ensino e aprendizagem, é mais uma face cruel das desigualdades que convivemos, ilustra essa última afirmativa as recentes propagandas do Exame Nacional do Ensino Médio (ENEM) que se quis realizar, mesmo durante a pandemia, as quais abordam um perfil juvenil elitista e que colocara em evidência o que, de fato, interessa a pauta governamental atual, em termos de federalização: a mais alta elite brasileira.

Dito isso, M1, M2 e M3, mulheres-mães das camadas populares, as quais foram colaboradoras deste estudo, encontram-se no perfil socioeconômico das famílias pertencentes à classe trabalhadora que encara a escola e a educação, consequentemente, como meios de ascensão social para seus filhos e enxergam nos conhecimentos matemáticos possibilidades de inclusão social dos sujeitos em uma sociedade letrada, quando destacam que a importância que a Matemática parece ter na formação das crianças:

[...] eles [referindo-se aos filhos] vão ser bastante inteligentes vão saber somar, não vão ser enganados com números, muito importante, nossa... M1 (Entrevista Concedida em 08/05/2020).

[...] porque ela é a base, né?! Além de ser uma matéria escolar curricular, é uma base, acho que ali ele [o filho] vai e decidir se ele vai seguir e buscar uma área que ele vai trabalhar mais com a Matemática porque até na Ciência você precisa da Matemática, então, eu acho que a Matemática, ela é a base de tudo, né?!. M2 (Entrevista Concedida em 13/05/2020).

[...] porque tudo hoje envolve a Matemática, desde um alimento, uma comida que você vai preparar até uma coisa maior vai Matemática e ela [sua filha] tem uma facilidade para a Matemática, a gente percebe essa facilidade bem grande com a Matemática. M3 (Entrevista Concedida em 13/05/2020).

Temos, nas falas postas em apreciação, indícios de formas de legitimação do conhecimento formal que a Matemática representa para essas famílias quando questionamos sobre as razões do porquê aprendê-la é relevante na trajetória escolar das crianças. O papel que este tipo de conhecimento parece exercer no cotidiano, nas habilidades mentais e ainda em situações de seu uso social (sistema monetário) foram aspectos destacados pelas mulheres como fundamentais e de reconhecimento do "peso" que a disciplina tem na vida de seus filhos e, portanto, de valorização nas atividades escolares. Com o ensino remoto, muitas tarefas são encaminhadas para casa, as quais passam a exigir estratégias de mediação entre competências/habilidades matemáticas para o desenvolvimento da aprendizagem dos alunos. Ao assumir, mais este papel, a mulher-mãe, necessita reorganizar sua rotina de trabalho diário e incorpora a prática de ensino como ação prevista no cotidiano, o que exige, sem dúvida, disciplina, conhecimento e organização.

As mulheres colocaram que o distanciamento social trouxe mudanças em suas rotinas familiares, como acréscimo do ensino remoto como atributo das atividades domésticas, somando mais uma tarefa para além das tantas outras já existentes em seus cotidianos. No entanto, todas relataram como positivo o fato de poderem estar em casa e passar mais tempo com os filhos, como exprimem, a título de ilustração, os relatos:

Estou podendo curtir ela [a filha] mais porque antes era muito difícil. M3 (Entrevista Concedida em 13/05/2020).

[...] agora fico mais tempo em casa, isso é bom para mim, posso ter mais tempo com as crianças, posso fazer algumas coisas com elas que eu não tinha mais tempo de fazer e agora eu tenho. M2 (Entrevista Concedida em 13/05/2020). 
No tocante ao coronavírus, todas entrevistadas afirmaram que a COVID-19 é provocada por um vírus, e que em caso de haver o desenvolvimento da doença, pode ser letal. A higienização das mãos, o uso de álcool em gel e de máscaras foram apontadas como as principais medidas adotadas para a prevenção. O distanciamento e o isolamento sociais também foram apontados, mas relataram dificuldade em realizá-los integralmente, bem como dúvidas quanto a sua eficácia e necessidade:

Eu ia visitar muito a minha mãe, que mora em outra cidade e a minha irmã, que está doente, isso mudou, porque eu não posso ir mais, a gente só vai visitar de vez em quando. M3 (Entrevista Concedida em 13/05/2020)

Eu acho que vai ter as consequências muito sérias em relação à economia, muita gente ficando desempregada isso vai ser muito pior. [...] fica a dúvida também para a gente se isolamento dá certo, se a pessoa não saiu, como que ela pegou, como tem suspeita e outros casos que a gente fica sabendo na cidade que a pessoa pegou, foi confirmado, mas não saía, estava em isolamento sem contato, como que ela pegou a não ser de casa, não teve contato com outras pessoas. M2 (Entrevista Concedida em 13/05/2020).

O distanciamento possibilitou ainda, nas formas de reorganização das rotinas das mulheres, uma demanda de tempo específico para as atividades de estudo. A M1 afirma: "nos organizamos depois do almoço, estudamos todos os dias", frente à isso, sabemos que a quarentena se apresentara difícil para alguns grupos, dentre os quais destacamos as mulheres. "As mulheres são consideradas «as cuidadoras do mundo», dominam na prestação de cuidados dentro e fora das famílias (...) Com as crianças e outros familiares em casa durante 24 horas, o stress será maior e certamente recairá mais nas mulheres” (SANTOS, 2020, p. 15-16).

Em termos das estratégias no auxílio nas tarefas, é possível identificar que as mulheres entrevistadas procuram recursos para ajudar e a potencializar, ainda mais, o desenvolvimento dos cálculos com as crianças.

Olha, eu busco nos joguinhos sabe, ler e contar no Play Store eu baixo e lá, ajuda muito nas continhas, nas sílabas, ele é muito bom! M1 (Entrevista Concedida em 08/05/2020).

Quando ele precisa fazer a continha dupla né, em cima e embaixo, então ele vai somar, daí ele fala: aaaaaaah mãe e agora? Um exemplo, você tem dois dedinhos, ele quer saber a conta $2+3$ daí eu falo: você tem dois dedinhos e você vai ganhar mais três dedinhos, então eu ensino ele a contar nas mãozinhas, nos dedinhos ou fazer risquinhos de pauzinhos ali ele vai eliminando ou vai acrescentando. M2 (Entrevista Concedida em 13/05/2020).

Para resolver... a gente vai mais com a cabeça mesmo, a gente não pega nenhum recurso, nada mesmo, né?! É mais... na cabecinha, explicação mesmo. [...] ela [a filha] mesmo já tem essa facilidade essa coisa de contar no dedo já ir na mente é muito boa para somar na cabeça [...]. M3 (Entrevista Concedida em 13/05/2020).

As crianças da atualidade são nativos digitais, elas já nascem em uma sociedade tecnológica. Portanto, se apropriar de recursos tecnológicos têm sido um ponto importante, é uma estratégia potencializadora para o desenvolvimento da aprendizagem numérica das crianças, assim esse movimento é uma das tendências em Educação Matemática importante para este cenário.

Outra fonte de estratégia pertinente, do ponto de vista do conhecimento matemático, é a adoção de um “esquema de ação" próprio como é o caso do "contar nos dedos”, sendo este um tipo de recurso que possibilita a visualização e experimentação pelas crianças. Consequentemente, quando as crianças contam nos dedos, elas estão visualizando e experimentando se apresenta com uma característica importante porque é um conhecimento informal do sujeito letrado. Infelizmente, muitas vezes, as famílias não reconhecem tais estratégias como pontos 
potencializadores do processo de aprendizagem no início da escolarização, justamente pelo "peso” que a Matemática escolar e/ou as marcas que o registro do cálculo escrito deixam em suas trajetórias enquanto instrumento de poder, ou seja, para se "saber Matemática” é preciso "fazer de cabeça”, registrar o que se pensa de forma objetiva. Assim, o cálculo mental, como foi o caso de M3, surge um princípio fundamental, a qual é um dos primeiros indicativos para o sentido de número, ao pensar em estratégias diferentes com a "cabeça/mente”, o sujeito aprendiz pode revelar sua destreza com números e "[...] a importantes capacidades como o cálculo mental flexível, a estimativa de quantidades numéricas e os julgamentos quantitativos” (SERRAZINA, 2012, p. 16).

Destaca-se, então, que estas são as três estratégias que as famílias colaboradoras entrevistadas estão utilizando para auxiliar seus filhos: 1) tecnologias (aplicativos e jogos digitais); 2) esquemas de ação (visualização/ experimentação); e 3) incentivo ao cálculo mental.

\title{
5 CONSIDERAÇÕES FINAIS: O QUE É POSSÍVEL CONCLUIR PARA O MOMENTO?
}

\begin{abstract}
A jornada pandêmica em nosso país é dupla: a primeira contra o vírus que nos tira o ar e, a segunda, contra outro vírus que nos tira do sério, a crise no governo. E nos convoca a rir de nossa situação. $\mathrm{O}$ que seria de nós, brasileiros, sem o riso em momentos tão assombrosos como esse? (BEREZOSCHI, 2020, p. 16).
\end{abstract}

Independente das formas de ajuda com a educação escolar das crianças, as famílias brasileiras estão vivendo um dilema: a inclusão [ou seria exclusão] digital. Sem dúvida, o momento histórico tem sido um prenúncio de que novos tempos virão, a escola, os alunos e as famílias não serão mais os mesmos quando tudo isso passar [e vai passar]. Contudo, o momento exige cuidado, uma vez que, muitos pais, mães e responsáveis não utilizavam muito os recursos tecnológicos, isso por não terem a conhecimento/apropriação ou ainda, nos casos mais extremos, o acesso. Vivemos em um país em que não é possível afirmar, acertadamente, que todos têm internet/computador em casa. A preocupação de uma das mulheres exprime o que estamos a dizer:

[...] no meu caso, eu não tenho computador na minha casa e o... [filho] acompanha pelo meu celular. Se ele vai fazer alguma atividade, é tudo pelo meu celular, se eu estivesse trabalhando, ele só conseguiria ter acesso a noite e têm pais que estão assim. O pai, a mãe... estão trabalhando, só chega em casa... só no final da tarde é.... (pensativa), então, a hora que estava lá (nas plataformas digitais) a aula de manhã, por exemplo, a criança pode até ter assistido, mas não consegue entender 100\% para fazer, e os pais... assim.... sem acesso... não conseguiam auxiliar, [...], então, ela [A PROFESSORA] manda esse link gravado, você consegue ter acesso a qualquer momento, assiste e pode ajudar a criança. M2 (grifo nosso).

A dificuldade destacada é consensual para a maior parte das famílias, algumas, mesmo não conhecendo bem ainda as plataformas digitais das atividades remotas acabam, pela força do cenário atual da COVID-19, sendo "motivadas" a estarem inclusas digitalmente para ensinar seus filhos, isso apresenta-se, para nós, como um problema, pois nem todas conseguem acompanhar em tempo real e/ou na proporção em que são "cobradas" para que as crianças estejam em dia com as tarefas encaminhadas à casa.

As mulheres, ao serem questionadas sobre quem auxilia nas tarefas escolares, reafirmam que são elas as protagonistas. Contudo, dentre as três entrevistas, duas exprimem evidências de que o conhecimento relativo ao campo da Matemática, particularmente, parece estar atrelado a uma questão de gênero, ao destacarem a figura masculina (os pais) como tendo melhor desempenho em cálculos. Tal dado não foi aqui explorado, mas anuncia pontos que merecem destaque o papel que o conhecimento matemático representa às mulheres e sua necessária instrumentalização neste campo, haja visa que mobilizam uma série de habilidades matemáticas nas tarefas diárias e na chefia da casa, para algumas. Sem dúvida, isso implica reconhecer que o mundo letrado exige dos sujeitos adultos (mulheres e homens), independente do gênero, formas de adoção do conhecimento matemático na vida para sua inclusão social em uma perspectiva matemática que vai além dos saberes escolares, o que reforça a necessidade de se conhecer os contextos culturais de aprendizagem das crianças (família). 
Do contributo que propusemo-nos realizar, com o compartilhamento destes escritos, fica, do lugar que falamos/escrevemos, a reflexão de que se faz preciso, processos de integração em programas de educação e saúde, os quais busquem promover a formação do pensamento crítico e a argumentação necessária ao debate e enfrentamento da crise instaurada nesta quarentena em que é reiterado o “\#FiqueEmCasa”. Findamos o trabalho com um sentimento de incerteza, porém, esperançosos de que dias melhores virão...

\section{REFERÊNCIAS}

BEREZOSCHI, J. Em busca do riso ético perdido. Boletim “Expressões em tempos de pandemia”. Vol. 5. 2020. p.15-17. Disponível em: http://www4.pucsp.br/nexin/expansoes-da-pandemia/expressoes-da-pandemiavol-5.pdf. Acesso em: 25, maio 2020.

BOGDAN, R; BIKLEN, S. Investigação qualitativa e educação: uma introdução à teoria e aos métodos. Portugal: Porto Editora, LTDA, 1994.

BRASIL, Ministério da Saúde. Coronavírus (COVID-19). Brasília, 2020. Disponível em: https://coronavirus. saude.gov.br/sobre-a-doenca\#o-que-e-covid. Acesso em: 09, maio 2020.

CANDIDO, D. da S.; WATTS, A.; ABADE, L.; KRAEMER, M. U. G.; PYBUS, O. G.; CRODA, J.; OLIVEIRA, W. de; KHAN, K.; SABINO, E. C.; FARIA, N. R. Routes for COVID-19 importation in Brazil. Journal of Travel Medicine, 2020. Disponível em: https://academic.oup.com/jtm/article/27/3/taaa042/5809508. Acesso em: 16, abr. 2020.

CARTA DE BRASÍLIA, Documento Resultante do Fórum Nacional Declaração de Helsinki: Perspectivas da Sociedade Brasileira. Brasília: Anis - Instituto de Bioética Direitos Humanos e Gênero/ Conselho Federal de Medicina/Fundação Oswaldo Cruz, 2000.

ESPÍNDOLA, A. L.; SOUZA, N. M. M. de. Contextos e práticas sócio-culturais de letramento e letramento matemático inerentes às relações família/escola. Zetetiké (UNICAMP), v. 18, p. 67-87, 2010. Disponível em: https://periodicos.sbu.unicamp.br/ojs/index.php/zetetike/article/view/8646670/13572. Acesso em: 14, maio 2020.

MCINTOSH, A.; REYS, B.; REYS, R. A proposed framework for examining basic Number Sense. For the Learning of Mathematics, Canadá, v. 12, n. 3, p. 2-44, 1992. Disponível em: https://flm-journal.org/ Articles/94F594EF72C03412F1760031075F2.pdf. Acesso em: 30, out. 2019

OPAS, Organização Pan-Americana da Saúde. Folha informativa - COVID-19 (doença causada pelo novo coronavírus). Brasília, 2020. Disponível em: https://www.paho.org/bra/index.php?option=com_ content\&view=article\&id=6101:covid19\&Itemid=875. Acesso em: 22, abr. 2020.

SANTOS, B. de S. A cruel pedagogia do vírus. EDIÇÕES ALMEDINA, S.A. 2020. Disponível em: https:// www.cpalsocial.org/documentos/927.pdf. Acesso em: 18, maio 2020.

SÃO PAULO Governo do Estado. Decreto n 64.862, de 13 de março de 2020. Diário oficial do Estado de São. São Paulo, v. 130, n. 63, p. 01, 2020a. Disponível em: http://diariooficial.imprensaoficial.com.br/nav_v5/index. asp?c=4\&e=20200331\&p=1. Acesso em: 24, abr. 2020.

SÃO PAULO, Governo do Estado. Decreto No 64.881, de 22 de Março de 2020. Diário oficial do Estado de São. São Paulo, v. 130, n. 57, p, 01, 2020. Disponível em: http://dobuscadireta.imprensaoficial.com.br/default. aspx?DataPublicacao=20200323\&Caderno=DOE-I\&NumeroPagina=1. Acesso em: 24, abr. 2020. 
SAWAIA, B. B. Apresentação. Boletim "Expressões em tempos de pandemia”. Vol.1. p.03-05. 2020. Disponível em: http://www4.pucsp.br/nexin/expansoes-da-pandemia/expressoes-da-pandemia-vol-1.pdf. Acesso em: 27, maio 2020.

SERRAZINA, M. de L. O sentido do número no $1^{\circ}$ ciclo: uma leitura de investigação. Boletim GEPEM. Seropedica: Rio de Janeiro, n. 61, p. 15-28, jul./dez. 2012. Disponível em: http://doi.editoracubo.com.br/10.4322/ gepem.2014.011. Acesso em: 28, maio 2020.

SOUSA JÚNIOR, J. H. de; RAASCH, M.; SOARES, J. C.; RIBEIRO, L. V. H. A. de S. Da desinformação ao caos: uma análise das Fake News frente à pandemia do Coronavírus (COVID-19) no Brasil. Cadernos de Prospecção - Salvador, v. 13, n. 2, Edição Especial, p. 331-346, abril, 2020. Disponível em: https://portalseer. ufba.br/index.php/nit/article/view/35978/20912. Acesso em: 25, maio 2020. 